\title{
El Políptico de la Familia Bravo de Lagunas, obra de Jan Sanders van Hemessen. Nuevas investigaciones
}

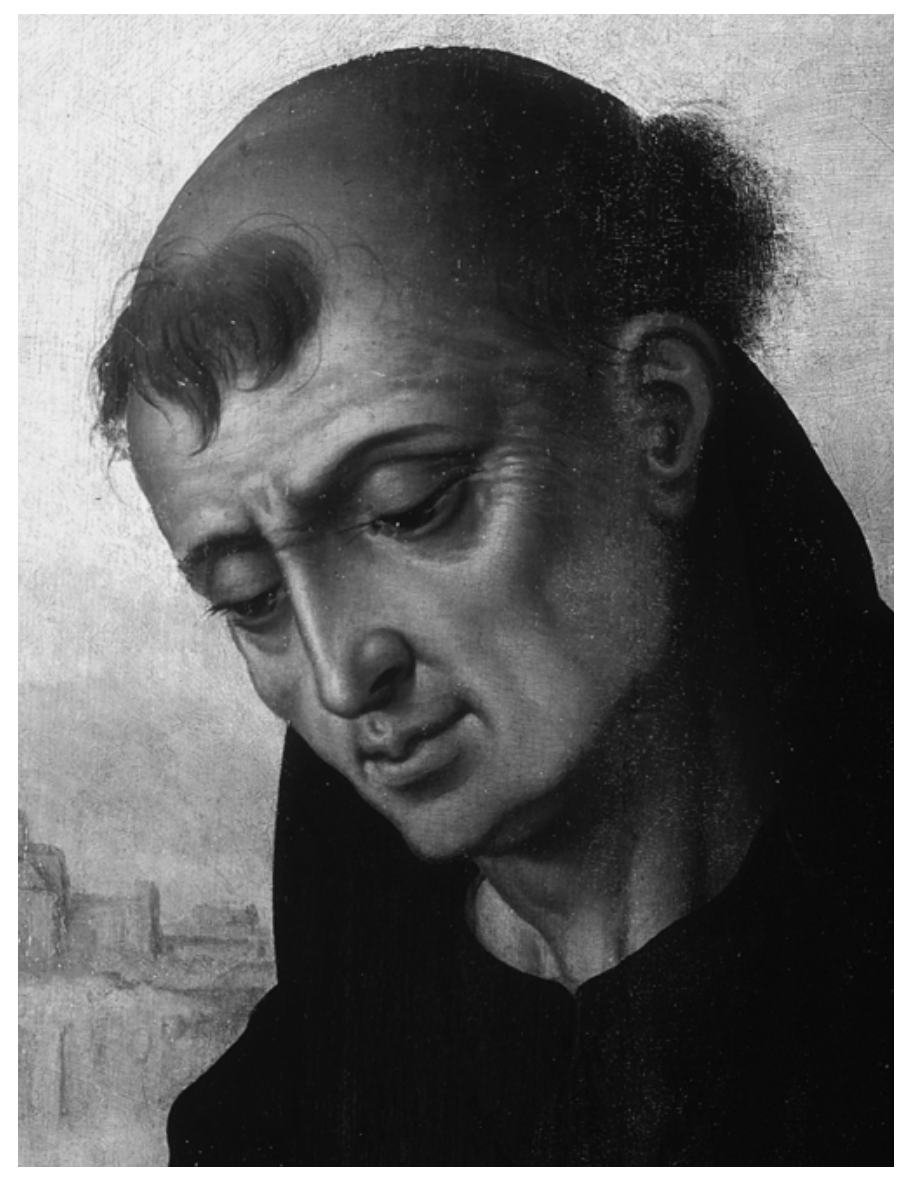

Lorenzo Pérez del Campo

Jefe del Centro de Intervención en el

Patrimonio Histórico

Instituto Andaluz del Patrimonio Histórico

\section{Resumen}

Este artículo proporciona información sobre una importante pieza del patrimonio histórico de Andalucía. Se trata del políptico la familia Bravo de Lagunas, pintado en Amberes por Jan Sanders van Hemessen entre 1540 y I 544 y conservado en la iglesia de San Vicente (Sevilla). Se ofrecen datos que permiten encajar la obra en el catálogo del artista al tiempo que se da a conocer por vez primera la correcta morfología del políptico, así como las circunstancias que rodearon su encargo y desmembración en el siglo $X V I I$. También se identifican los retratos de los per- sonajes históricos que se representan en una de las hojas del conjunto y se analizan los contenidos del programa decorativo y funcional trazado por el comitente hacia 1539, del que el políptico es la pieza central.

\section{Palabras clave}

Pintura flamenca sobre tabla / Siglo XVI / Jan Sanders van Hemessen / Retrato / Manierismo

En 1987 el profesor Juan Miguel Serrera' tuvo ocasión de estudiar dos tablas conservadas en la parroquia sevillana de san Vicente que, aunque no firmadas ni documentadas, relacionó con el pintor flamenco Jan Sanders van Hemessen (Hemishen, c. I500-Haarlem,c. I556), uno de los más reputados pintores del siglo XVI en los Países Bajos². Estas 
0
1
$z$
$\Sigma$
$\Sigma$
0
0
0
0


Fig. I Políptico de la familia Bravo de Laguna. Puertas laterales. Interior. "San Benito con los caballeros Bravo de Lagunas y Alfaro" y "San Roque y San Sebastián". (Fotografía: E. Fernández Ruiz)

Fig. 2. Políptico de la familia Bravo de Laguna. Puertas laterales. Exterior. "Arcángel san Gabriel" y "Virgen anunciada". (Fotografía: E. Fernández Ruiz). (antes de 1489-después de 1520) y más tarde se relaciona con Jan Cornelis, Jan Gossart y Marinus van Reymerswale. En I520-2I conoce a Alberto Durero durante la estancia de éste en Antwerp. El gran maestro alemán ejerció una profunda influencia en el joven Jan. Precisamente en este último año Durero pinta su "San Jerónimo meditando en el desierto" por encargo de Rodrigo de Portugal, obra que atraerá el interés de nuestro artista y por la que sentirá especial predilección. Ciertos datos confusos hacen pensar que en estos años Jan van Hemessen practicó la escultura. También se registra una posible estancia en Florencia, Roma y Norte de Italia en la que parece que copia el fresco de la "Caridad" original Andrea del Sarto (Florencia, Chiostro Scalzo). Está probada su presencia en la corte de Fontainebleau en sucesivas visitas realizadas entre 1530 y I540. A Jan van Hemessen se le incluye en el grupo de pintores manieristas de sensibilidad ecléctica; la crítica especializada ha puesto de relieve las relaciones entre su pintura y la de Vicent Sellaer, que estuvo en Italia hasta I 544 y con quien pudo coincidir en algún viaje. No obstante a lo largo de su carrera Hemessen criticó duramente los valores del gótico perfeccionando el lenguaje manierista con la incorporación a su estética de nuevos conceptos altorrenacentistas (forma, espacio y luz), a través de los que formula una atractiva articulación tangible de la realidad.

En 1535 Jan van Hemessen es un artista consolidado. Acepta un aprendiz (M. Huysmans) y casa con Bárbara de Fevere, hija de Simón de Fevere, próspero comerciante de diamantes de Amberes. Entre 1530 y I 540 nuestro artista desarrolla un tipo de pintura sobre tabla que aún hoy se asocia a su nombre: composiciones alargadas, retratos en grupo con figuras subsidiarias, escenas realistas con pequeños detalles de la vida urbana. En esta época sus obras forman parte de lucrativas exportaciones a Portugal y España a cambio de cochinilla de las Indias, muy necesaria para la industria textil flamenca. En la década de los cuarenta, su estilo es, básicamente, una sofisticada expresión del manierismo internacional; en su taller de Amberes desarrolla una importante actividad artística que le hace relacionarse con prestigiosos personajes de la época.

Jan Sanders fue un hombre de su tiempo que siguió muy de cerca la polémica político-religiosa desarrollada en Europa y, más concretamente, en su entorno geográfico, sirviéndose de su arte para informar de algunas opiniones. Su aventajada posición social y calidad artística le hizo participar en 1549 en los trabajos del "Triunfo de Amberes", suntuosas decoraciones realizadas por encargo del gobierno de aquella ciudad para conmemorar la entrada de Carlos $V$ y el futuro Felipe II.

Al final de su vida ( 1556 ) recibió otro importante encargo de España. En ese año don Iñigo López de Mendoza, conde de Tendilla, le encargó con destino al testero principal de la iglesia del Monasterio jerónimo de Santa Ana (Tendilla, Guadalajara) un retablo pictórico que hoy se conserva en el Cincinnati Art Museum y que presenta ciertas relaciones con la 
obra Sevilla 5 . A la muerte de Jan la obra fue concluida, entre otros artistas, por su hija Caterina (Amberes, I528-1587), instalada en España como pintora de cámara de la reina María de Hungría (I5051558), hermana de Carlos V, quien la dotó espléndidamente en su testamento.

\section{Las tablas de la iglesia de san Vicente}

Se trata de las puertas de un políptico, de $206 \times 100$ centímetros. Las tablas tienen representaciones figurativas a ambos lados, como correspondía a su función. La situada a la izquierda en origen representa en su interior a San Roque y San Sebastián y la situada a la derecha a San Benito y tres caballeros orantes. En el exterior, aparece pintada en grisalla la escena de la Anunciación (arcángel San Gabriel y Virgen María a la izquierda y derecha, respectivamente).

Ambas puertas fueron identificadas como procedentes del tríptico de la familia Alfaro que presidía la capilla de Santa Catalina en la citada parroquia.

Ya se ha explicado en las páginas de esta misma revista que el estado de conservación de las tablas aconsejó su restauración en el Instituto Andaluz del Patrimonio Histórico, en cuyo Taller de Pintura fueron sometidas, entre 1986 y 1988 a diversos tratamientos 6 .

Los nuevos estudios que presentamos suponen un avance en el conocimiento de la historia material de la obra y aportan datos que permiten conocer la exacta morfología del políptico, así como algunos avatares sufridos por sus piezas a lo largo de los años; cabe indicar que hasta el momento no se tenían noticias del políptico desde 1540 y hasta I884, en que Justi ve las tablas de referencia en el pórtico norte de la parroquia. (Serrera, 1987). También se ha logrado una aproximación a la realidad de los personajes representados que se identifican exactamente como Don Sancho Bravo de Lagunas y Alfaro y sus hijos Diego y Luis.

\section{El políptico y su morfología}

I. La historiografía especializada ha venido considerando que el retablo del que formaban parte las tablas estaba compuesto por las citadas dos puertas de madera pintada, un relieve central también flamenco posiblemente obra de un maestro de Amberes y un remate con una pintura del Crucificado, presumiblemente del pincel de Hemessen. (Serrera, 1987). Esta interpretación se ha venido fundamentando, en lo documental, en el Libro de bienes muebles de la iglesia de san Vicente Mártir de Sevilla, fechado en 15407.

La transcripción publicada, a pesar de su interés por citada la proximidad cronológica a la construcción e instalación del retablo pone de manifiesto algunos importantes problemas en relación con la morfología de la obra. Si efectivamente la zona central era relieve y, además, en su centro se disponía la santa mártir "en bulto", era evidente que el retablo, al cerrarse, tendría muy considerables dificultades para encajar, lo que parece absurdo; por otra parte, esa concreta morfología es muy infrecuente en el mundo flamenco y no se conoce ejemplar de esas características en el catálogo de Hemessen.

Para aclarar estos aspectos era necesaria la localización de alguna descripción fidedigna del retablo realizada antes de su desgraciado desmembramiento. Esta información debía existir, ya que es difícil concebir que un hipotético relieve de gran formato $(2 \times 4$ metros aproximadamente) hubiera pasado desapercibido durante trescientos años; incluso su mero traslado habría exigido una buena cantidad de mano de obra, que era necesario contratar ex-profeso y cuyo salario estaría registrado, sin duda, en la minuciosa contabilidad de la Hermandad Sacramental o de la fábrica parroquial, según procediera.

II. En 1680 el marqués del Prado instó en la Vicaría General del Arzobispado de Sevilla un procedimiento judicial tendente a recuperar la posesión de la capilla de Santa Catalina, que a la sazón disfrutaba la Hermandad Sacramental de la citada parroquia ${ }^{\text {, }}$ mediante reconocimiento de su derecho de patronato. Esta circunstancia parece que se venía produciendo desde comienzos del siglo XVII tras haber interrumpido los patronos sus obligaciones pecuniarias hacia la fábrica. La resolución del procedimiento (sentencia de 15 de abril de 168 I) fue desfavorable al noble quién no vio reconocida su pretensión, continuando en consecuencia la Hermandad Sacramental en la posesión del inmueble y su patrimonio. La capilla en litigio se localizaba concretamente "en el rincón de mano derecha entrando por la puerta de la Iglesia que está enfrente de las casas de Juan de la Fuente", en un lugar que forma parte del espacio ocupado desde el siglo XVIII por la nueva y magnífica Capilla Sacramental trazada por los arquitectos Pedro de San Martín y Lucas Cíntora?.

Junto con los resultados de la sentencia, que no fue apelada y devino firme en virtud de ejecutoria de 9 de agosto del mismo año, el estudio del sumario del proceso es de extraordinaria importancia para el conocimiento de interesantes aspectos de la historia material del retablo y de determinadas circunstancias de su construcción gracias a de la calidad informativa de las actuaciones de las prácticas de prueba y por el conocimiento de las personas intervinientes 10 .

También proporciona el proceso importante información sobre la morfología original del retablo. En este sentido, en el documento de peticiones formulado por los procuradores del marqués se aporta un primer dato de importancia: la existencia en la capilla en litigio de "... un retablo y en el pintados los 


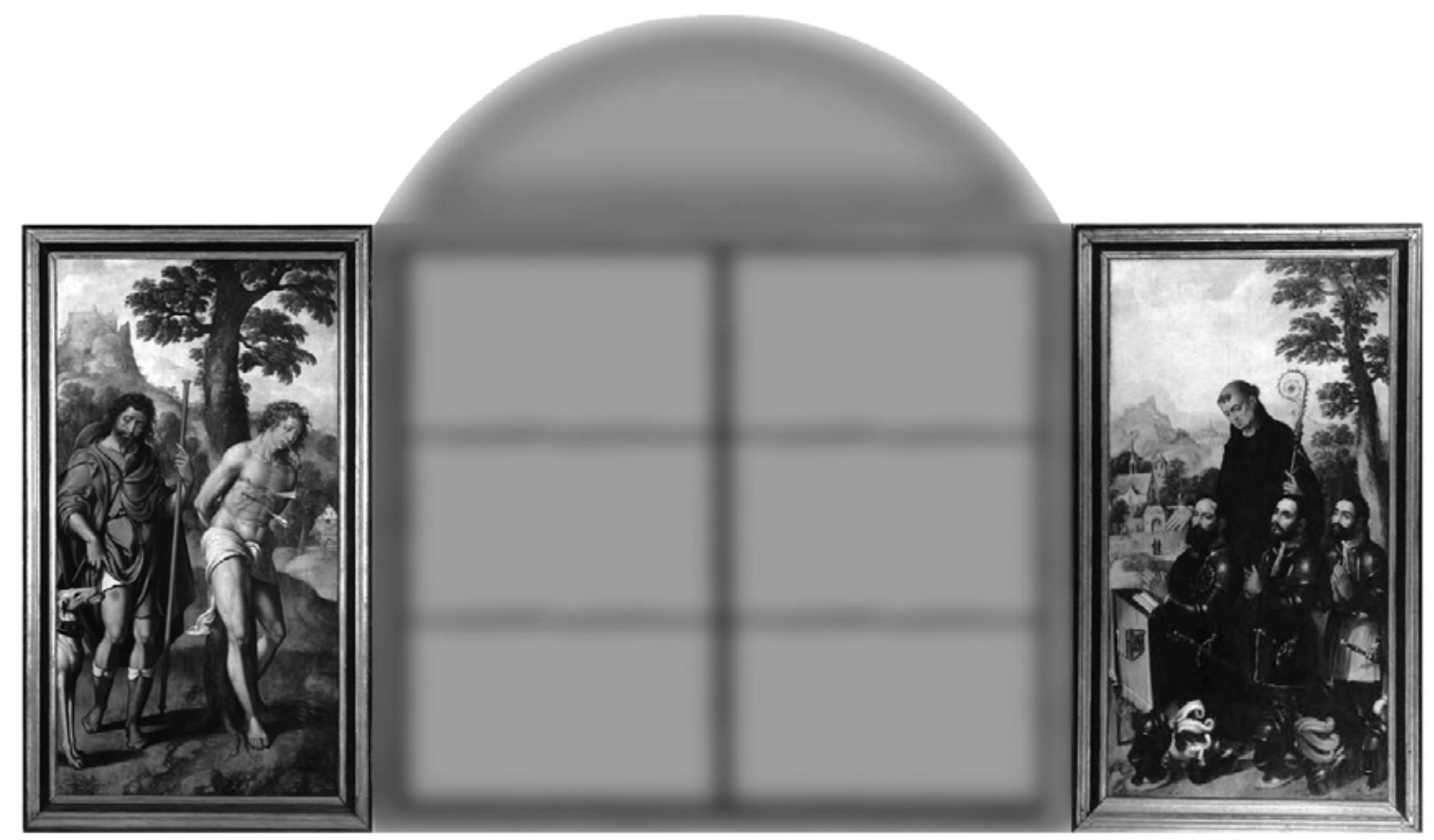

Fig. 3. Políptico de la familia Bravo de Lagunas. Propuesta de restitución volumétrica. (Fotografía y tratamiento gráfico: E. Fernández Ruiz) martirios de la Santa en diferentes divisiones y en ellos efigies de la familia de una parte con su escudo de armas..." $\left(60 v^{\circ}\right)$.

Comenzaba a esbozarse una morfología de la parte central del retablo sustancialmente distinta a la propuesta por la crítica. No obstante, el exacto y definitivo conocimiento de la realidad se desprende de otro de los documentos obrantes en autos. Se trata del acta notarial suscrita por el escribano público Juan Antonio Guerrero que corresponde a la práctica de prueba realizada el 14 de junio de 1680 II. En la mañana de ese día el escribano, que actuaba a instancias del procurador Pedro de Ayala, representante del marqués, se personó en "la iglesia de San Vicente para hablar con diferentes ministros de la Iglesia a quienes pregunté en que sitio y parte estaba el retablo antiguo que estaba en la capilla de Santa Catalina... y los dichos ministros me guiaron a una capilla... y habiendo entrado en ella... reconocí un retablo antiguo que estaba arrinconado en la pared de dicho sitio el cual se componía de cuatro piezas de madera que las dos de ellas servían de puerta. Y habiendo reconocido sus pinturas parece que las dos piezas de en medio están divididas en seis láminas pintadas en tabla y en ellas diferentes martirios de Santa Catalina. Y en una de las dichas dos puertas que serán de dos varas y media de alto parece estar pintado en tabla San Sebastián y San Roque. Y en la otra puerta parece estar pintado San Benito y tres retratos que están de rodillas tres personas armadas y los dos de ellos tienen sobre el pecho una encomienda que parece ser de Posesión de Alcántara y junto a ellos un escudo de armas".

El acta incorpora un minucioso dibujo de este escudo de armas, realizado por el mismo notario, coincidente en todo con el que podemos contemplar en la puerta de san Benito y los caballeros 12. El citado escudo fue identificado por Gabriel Ferreras y Rocío Magdaleno como perteneciente al linaje Alfaro y Bravo de Lagunas ${ }^{13}$.

Este segundo documento no deja lugar a dudas. Definitivamente el retablo era un políptico formado por cuatro grandes piezas de madera de igual tamaño; las dos hojas centrales estaban, a su vez, divididas por tablas pintadas, en número de tres por pieza. No aparece rastro alguno del hipotético relieve central. Tampoco aparecen referencias del ático (?) con la imagen a pincel del crucificado a que parece hacer mención el citado libro de inventario.

Además de lo aportado en la citada prueba, abundaron en esta descripción otros varios peritos y testigos que actuaban en defensa de las pretensiones de ambas partes. Entre ellos Juan Quintero, que informó, en relación con la parte central del retablo: “...están pintados los martirios de la santa en diferentes divisiones...". También declaró que la Hermandad Sacramental tomó posesión de la capilla de los Bravo de Laguna en 1630 siendo mayordomo de la corporación Luis Márquez Sánchez. Sabemos que en esta última fecha el conjunto experimentó una primera modificación, cuando el mayordomo mandó construir un banco de madera al retablo en cuyo centro colocó el Sagrario, por lo que hubo de ser desplazada la imagen de Santa Catalina. Esta modificación se mantuvo hasta 1676 fecha en que la Hermandad reconstruyó la capilla y bóveda y encargó un nuevo retablo al escultor F. Rivas (1677), desmontándose el pictórico.

A ese nuevo retablo se incorporó la escultura de la santa que fue convenientemente reencarnada por 
Lorenzo de Ávila 14. En relación con esta escultura, conocemos por el testimonio de Hermenegildo de Bustamante que portaba "una espada en la mano y una figura de hombre debajo de sus pies", es decir, seguía la iconografía clásica de la santa mártir.

Un importante escribano público de la época, Juan Muñoz Naranjo, apunta en su declaración que conoce muy bien la iglesia de San Vicente al haber nacido en esta collación, e insiste en que el retablo esta formado por tablas y que "... en las tablas antiguas esta la imagen de Santa Catalina...". Un tercer testigo coincide en que "...en las tablas centrales están pintados los martirios de la Santa en diferentes divisiones...".

Mayor novedad aporta el minucioso testimonio que el 30 de agosto de ese año ofrece Antonio del Castillo, contador municipal y de la Real Audiencia y veterano feligrés de san Vicente. Su declaración es minuciosa en detalles tanto de la imagen de la santa titular, (de la que nos confirma que "es de talla y a la redonda"), como de las pinturas centrales de los martirios. No obstante el mayor interés se centra en la información que proporciona de la morfología del retablo, explicitando que recordaba que "...el retablo era obado por arriba...". Esta importante referencia ha de ponerse en relación necesariamente con el calvario de pincel citado en el Libro de 1540 y cuya desmembración del resto del retablo hemos de darla por segura en junio de 1680, en atención a los contenidos de la citada acta notarial. Apuntamos la posibilidad que la citada pérdida se produjera en el traslado de 1676, tal vez consecuencia de la falta de espacio en la nueva ubicación del retablo: el exacto lugar en que lo encontró el notario. Éste se trataba precisamente de "...la capilla que está a mano izquierda de la capilla mayor...", espacio que debe identificarse con la capilla que luego sería de la Virgen del Rosario cuyo acceso estaba entonces en el presbiterio de la iglesia.

\section{El promotor y la cronología de la obra}

Como se ha indicado el políptico presidía la capilla de Santa Catalina: las capellanías de Santa Catalina y San Sebastián, en la iglesia de san Vicente Mártir, fueron instituidas en 1459 por el jurado de Sevilla Francisco de Alfaro y su hermano Juan de Alfaro, mediante escritura pública registrada ante el notario Rodrigo García. El régimen jurídico de Patronato fue acordado hacia 1480 por Garci Sánchez de Alfaro, hijo del segundo matrimonio del anterior y Aldara Bravo de Lagunas, su esposa, hija del alcaide de Gibraleón. En la concordia suscrita con la fábrica parroquial se acuerda, entre otros extremos, que ésta se obligaba a servir dos fiestas principales los días de ambos santos protectores con sus correspondientes sermones. Por varias razones, mediante escrituras de 3 de febrero y 14 de marzo de 1543, Sancho Bravo de Laguna, hijo de los anteriores y nieto de Francisco de Alfaro de una parte $y$, de nuevo, la fá- brica parroquial formalizaron un segundo concierto de Patronato 15. En este acuerdo se mantienen las fiestas señaladas y se aplican al culto rentas por valor de 14500 maravedises anuales. A cambio, el patrón obtiene plena autorización para "hacer a su costa todos los adornos e reparos que la capilla obiese necesidad". Consecuencia de este compromiso es la decisión de reformar en profundidad la capilla e instalar, entre otros bienes muebles, un retablo acorde con la importancia política y el prestigio social a que aspiraba la familia.

El mecenas del proyecto fue el citado Sancho Bravo de Laguna y Bravo Martínez de Montoya y Rodríguez, entonces patrón de la capellanía y hombre de gran ambición social. Nacido en 1488, ingresó en la orden de Alcántara en 153|16 y desempeñó el cargo de comendador de Peraleda. Comenzó su carrera política siendo nombrado maestresala del regente cardenal Ximenez de Cisneros gracias, sin duda, a su matrimonio con una sobrina del gran clérigo franciscano. Posteriormente fue regidor, entre otras, de las villas de Cisneros y Sahagún. Pudo entrar en contacto con el emperador quién lo nombró Teniente de la Fortaleza de los Bodonales ${ }^{17}$, miembro de su Consejo de Guerra, Veedor General de los ejércitos y armadas y Gentilhombre de Cámara. Don Sancho, aunque pasaba largas temporadas en la itinerante corte del emperador, residía en su casa familiar de la collación de san Vicente en Sevilla ciudad en la que tenía importantes negocios y propiedades, muchas de ellas de tradición familiar. Las capellanías de santa Catalina formaban parte importante de su patrimonio material y, sobre todo, afectivo "por haber pertenecido a mis padres y ahora es mía y yo soy de ellas patrón", como explicita en la escritura de concordia.

Sancho consolidó el régimen jurídico de la capellanía e hizo de la capilla panteón familiar. A tal fin negoció y obtuvo la bóveda de la capilla para enterramiento familiar, extremo que se recogió en la concordia citada. Obtenido el permiso proyectó una decoración acorde con su sólida posición social, económica y política que explicitara las devociones históricas familiares. En primer lugar hizo trasladar a san Vicente los restos de varios miembros de la familia fallecidos en Castilla.

El segundo paso era la ejecución material de la empresa artística. Del ambicioso programa arquitectónico y decorativo existen un buen número de referencias documentales que nos hablan de su calidad y de la elevada cuantía económica de lo invertido. Hacia I543 estaba concluida la nueva capilla y se ultimaba decoración, en la que se incluían retablo y pendones con la heráldica familiar. Sabemos de la satisfacción del patrono por su obra y de la admiración del mayordomo de la fábrica parroquial "por las muchas cosas que el dicho don Sancho ha echo en la dicha capilla e la adornado y acrecentado mucho". En opinión del mecenas este importante proyecto no era un lujo o un dispendio superfluo, sino algo absolutamente necesario y una destacada forma de representación del honor familiar 18. 
No obstante nada de estas obras ha llegado hasta nosotros con excepción del políptico de santa Catalina, encargado con toda seguridad en la propia ciudad de Antwerp (Amberes) donde Hemessen tenía abierto taller. Precisamente la estancia del comitente en Amberes ha de relacionarse con su presencia en el séquito y ejército que acompañaron al emperador en 1540 en los Países Bajos en la llamada campaña de Gante. Sancho Bravo de Lagunas, en su condición de Gentilhombre de Cámara de Carlos V y Veedor militar, formó parte de este séquito. Una vez resuelta de forma contundente la revuelta en la ciudad natal del emperador ( 14 de febrero- 12 de mayo), Carlos marchó a la próspera y cercana Amberes, ciudad en la que permaneció entre el jueves 13 y el lunes 24 siguientes con toda su Casa, Cámara y Consejo, según informan los documentos de la época. Está justificado pensar que, con esta ocasión, don Sancho entrara en contacto con nuestro artista y formulara el correspondiente encargo.

La cronología apuntada hasta el momento pudiera parecer que contradice lo transcrito por Serrera del Libro Inventario a que hemos hecho referencia más arriba. Si el encargo fue realizado en mayo de 1540 parece muy difícil la posibilidad de que un retablo de tal envergadura estuviera el mismo año instalado en la iglesia de San Vicente. Por otra parte, uno de los representados, Luis Bravo, no solicitó su ingreso en la Orden de Alcántara hasta junio de 1543 y resulta inconcebible que hubiera decidido lucir en su pecho, antes de la Real Cédula de concesión, la cruz de Alcántara. Bien es cierto que esta cruz pudo ser añadida con posterioridad, con lo que nos encontraríamos con un antecedente de lo que décadas más tarde sucedería con Diego Velázquez, pero no creemos que sea posible esta hipótesis por que tras estudiar detenidamente ambas cruces (la del padre y la del hijo) las encontramos de una absoluta similitud, trazadas con idéntica técnica y utilizando exactamente la misma composición cromática.

La explicación ha de ser buscada necesariamente en el propio Libro Inventario. En este sentido, es necesario indicar que la fecha de 1540 que aparece en la portada del volumen corresponde exclusivamente a la de apertura del libro y no a la de la totalidad de sus apuntes, que se extienden hasta |55|. En cada capítulo del Libro, se van anotando una tras otra, las obras existentes en el momento de la apertura del volumen y aquellas otras que se incorporaron entre esos años a las distintas capillas de la parroquia. También se anotaban tras cada obra, en su caso, las causas de desaparición o de los cambios habidos en su ubicación en el templo.

Si bien no se especifica la fecha exacta de cada revisión del inventario y, en consecuencia, no podemos conocer el momento concreto en que quedó registrado el retablo de van Hemessen, existen datos que nos inclinan a pensar que éste no quedó anotado en los apuntes de 1540. El primero y más importante es que el registro del retablo que estudiamos ocupa uno de los últimos lugares en el capítulo co- rrespondiente a "retablos y pinturas", y que el primer lugar, entre las piezas de la capilla de Santa Catalina lo ocupa este otro registro: "Ytem otro retablo de madera pintado de pinzel con la historia de Santa Catalinalesta en su capilla/pasó al monasterio del carmen para un altar" 20.

Como sabemos que el retablo de Hemessen nunca pasó al Carmen el citado anteriormente no puede ser el encargado por el caballero Bravo. También es impensable que hubiese dos retablos con exactamente el mismo programa iconográfico instalados en idéntico y reducido lugar. Por otra parte, el dato del traslado al vecino convento Casa Grande del Carmen está escrito con grafía distinta a la del resto de la nota. Por todo ello hemos de concluir que este primer retablo-del que carecemos de datos concretos- es el que existía en 1540 en la capilla de santa Catalina cuando se abre el inventario, y es anterior al programa de reformas impulsado por Sancho Bravo. La llegada de la obra de Amberes tuvo que motivar su traslado a la cercana iglesia del cenobio carmelita, como lo prueba el hecho que varios apuntes más adelante se registra el retablo de Hemessen.

Por todo ello opino que el políptico fue concluido en 1543 una vez hubo accedido a la condición de caballero de Alcántara Luis Bravo y fue instalado en la capilla de Santa Catalina en los últimos meses de ese año o a lo largo de 1544. Precisamente esta cronología coincide en el tiempo con la segunda concordia de Patronato entre los Bravo de Laguna y la Fábrica parroquial (suscrita en 14 de marzo de 1543) que, como hemos indicado, tuvo una inmediata consecuencia: la autorización eclesiástica para la realización de obras de mejora y ornato en la capilla, a cuyo programa corresponde el políptico.

Del análisis de la documentación disponible se desprende que los Bravo de Lagunas eran unos hombres de su tiempo. El modelo cultural en el que creían padre e hijo se sustantivaba en la conciencia de vivir una nueva época en la que la mentalidad laica pretendía romper los vínculos culturales tradicionalmente desarrollados por la Iglesia. Como han señalado Víctor Nieto y Fernando Checa (1989) "se produce una disociación sin traumas entre cristianismo y cultura laica surgiendo una emancipación con respecto al monopolio cultural ejercicio secularmente por la Iglesia" 21 . Las novedades de esta cultura no rompen con las creencias religiosas. Para este tipo de personaje el dinero es como la recompensa de Dios, por ello en las imágenes religiosas se representan a los personajes que las encargan también como símbolo de su status socio-económico.

El tríptico de Santa Catalina no es, en consecuencia, una mera composición religiosa dedicada a satisfacer íntimas inquietudes espirituales; no es sólo el resultado de la devoción de la familia Bravo de Lagunas. El retablo es, básicamente, el instrumento representativo y emblemático del comitente; es una absoluta proclamación de la virtud, del rango, del prestigio y 
de la condición de Sancho y su familia; en definitiva, supone la consagración del triunfo social de un hidalgo. Se trata de una composición encargada con una aparente finalidad votiva pero comporta una sofisticada interrelación de funciones: la ostentación de la idea de rango y magnificencia de los grandes varones de la familia. La forma en que éstos han sido figurados es, en este sentido, sumamente representativa: más que unos devotos agradecidos en actitudes recogidas, los nobles caballeros parecen los protagonistas devotos de una importante empresa militar.

El propio Sancho Bravo es el caballero de más edad de los tres representados en la tabla de la derecha en actitud orante y genuflexa delante de san Benito de Nurcia, protector y patrón de la Orden de Alcántara. Esta identificación ya fue propuesta con acierto por Ferreras y Magdaleno (1997) quienes, además, informan que los retratos de los otros dos caballeros corresponden a representaciones de hijos del citado Sancho 22

En relación con la personalidad de los representados podemos precisar aún más. Por el testamento de Sancho Bravo de Lagunas, otorgado en Madrid el II de diciembre de 1534, sabemos que casó dos veces. En la primera ocasión con María de Villarreal Cisneros, hija del Adelantado de Cazorla y señor de San Martín de la Fuente, García de Villarreal y de su esposa María Ximenez de Cisneros. De este enlace sólo tuvo un hijo varón Luis Bravo de Laguna y Cisneros Bravo y Jiménez, nacido primogénito de la familia en 1518 , quien fue capitán de la caballería de Carlos $\vee$ y perteneció a la orden de Alcántara, en la que ingresó en $1543^{23}$. En virtud del testamento de su padre, Luis fue dotado con la legitima de su madre, que ascendía a la fabulosa cantidad de 3000 ducados de oro. Por razón de residencia, la gestión de la fortuna fue encomendada a don Juan Barela, amigo del padre y jurado de Sevilla, quién la invirtió íntegramente en la adquisición de juros, heredades y propiedades inmobiliarias en la ciudad. La gestión del jurado fue un éxito y fundamentó otra importante carrera política: Luis fue nombrado Comendador de Los Hornos y fundó un importante mayorazgo. Su imagen corresponde a la del caballero que ocupa el centro de la representación.

En segundas nupcias Sancho Bravo casó con Bernardina Manrique de la Vega, con la que tuvo un único hijo: Diego Bravo Manrique de la Vega. En el testamento del padre, Sancho fue instituido como heredero de su hermanastro Luis en el caso de que éste muriese sin descendencia, circunstancia que no se produjo, ya que Luis fue progenitor de Sancho Laguna, comendador de Quintana, quién a finales del siglo $\mathrm{XV}$ l le sucedió en el derecho de patronazgo de Santa Catalina. Diego es el caballero representado a la derecha, el único que no luce en su pecho la cruz de la Orden de Alcántara.

Todos los retratos caracterizan perfectamente a los escogidos, al tiempo que sirven de soporte a sus glorias sociales y políticas. El retrato exalta la virtud y fijar la memoria de la familia en el tiempo. Pero como estaba destinado a formar parte de un lugar sagrado se caracterizan como hombres de guerra virtuosos y devoto, en consecuencia se hacen situar bajo respaldo y protección de la santidad como había visto en otras muchas obras flamencas.

Recientemente se han analizado las relaciones formales de la obra sevillana con el tríptico de San Sebastián del Petit Palais (tradicionalmente fechado hacia I530) y de forma especial con el tríptico del Juicio Final de la sint Jacobskerk de Antwerp, obra realizada entre 1536 y 1537. Los puntos de contacto entre el políptico de Santa Catalina y esta última obra son particularmente significativas; de forma especial en la representación de los caballeros de la familia Rockox protegidos por san Adrián que ocupan, precisamente, la tabla lateral izquierda del tríptico. Por otra parte, las precisiones cronológicas apuntadas en este trabajo permiten confirmar el antecedente inmediato de la obra conservada en Amberes con respecto a la sevillana. Cabe recordar que en ambas piezas es idéntico el tema iconográfico elegido para la grisalla del exterior de las puertas y que, en ambas se representan con las imágenes invertidas, invariante varias veces usado por Hemessen a lo largo de su carrera artística.

Por último indicar en relación con las tablas pequeñas con las escenas de la vida y martirio de santa Catalina, que se tratan de las "seis tablitas de la vida de Santa Catalina de Alejandría, sevillanas y del XVI, partes de un retablo también despiezado" que Hernández Díaz (1977) logró inventariar en la colecturía de la parroquia de san Vicente ${ }^{24}$.

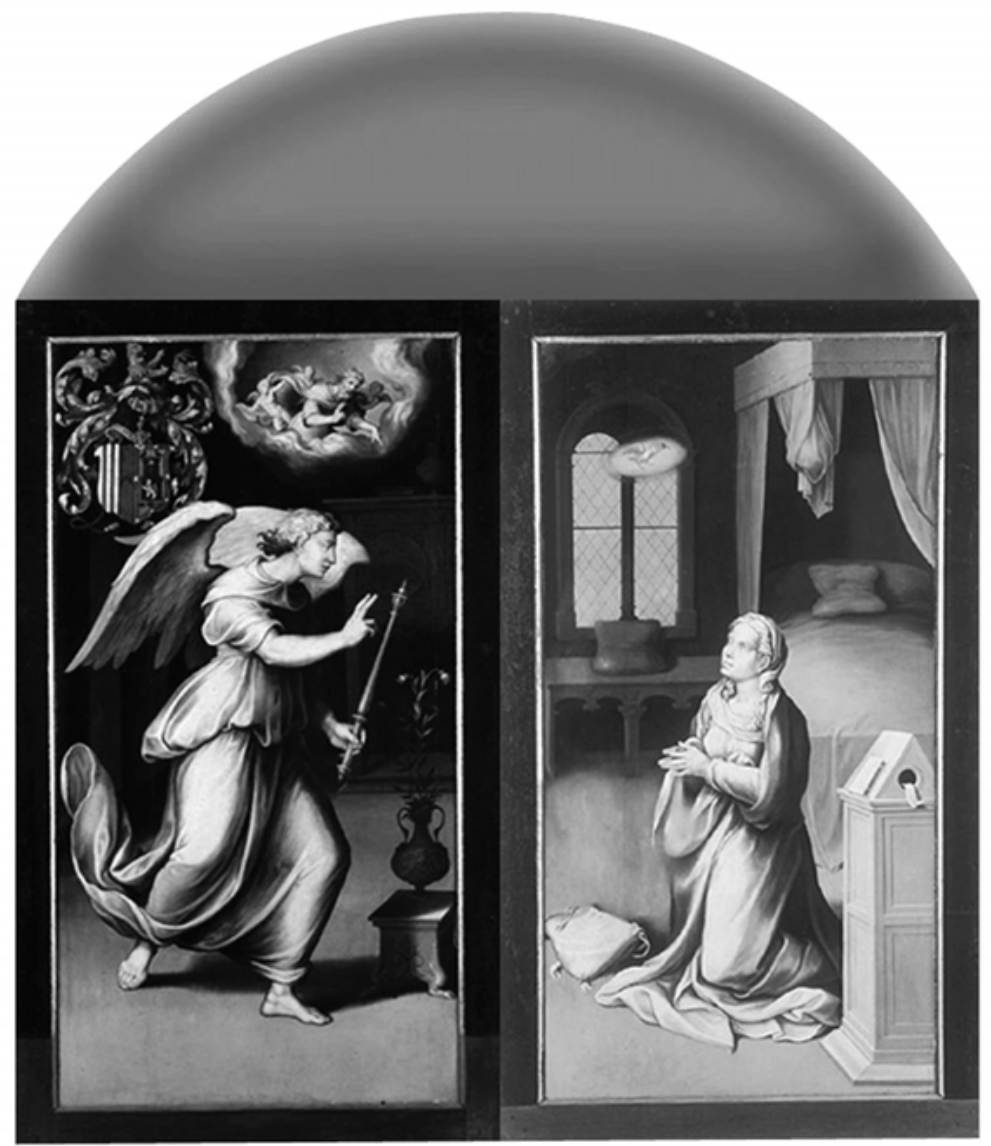


I. SERRERA, J.M. (1987): "Nuevas obras de Jan van Hemessen". Boletín del Seminario de Estudios de Arte y Arqueología. Tomo LIII, págs. 363-368. Valladolid.

2. VASARI, G.: Vida de los más ilustres pintores, escultores y arquitectos. Vol. IV Artistas flamencos.

3. JUSTI, C. ( I 884): "Peeter de Kempeneer genant Maese Pedro de Campaña" en Jarbuch der Königlich Preuszinchen Kunstsammlungen p. I70.- GESTOSO Y PÉREZ, J. (I 889) Sevilla Monumental y Artística, pág. 270-27I.- MAYER, A.L.(|9|I): Die Sevillaner Malesrchule. Beiträge zu ihr Geschichte pág. 46. Lepizig.

4. WALLEN, Burr (1983): Jan van Hemessen. An Antwerp painter between Reform and Counter-Reform. Michigan, UMI.- FRIEDLANDER, Max J.(1968): Early Netherlandish painting. Leyden.

5. GARCIA DE PAZ, J.L. (1998). "El Retablo del Monasterio de Santa Ana de Tendilla". Diario Nueva Alcarria, 19 de junio de 1998.

Se ignora la fecha de salida del retablo de España. El retablo no se menciona en los documentos de la Comisión Provincial de Monumentos de Guadalajara de 1845. Se sabe que en 1915 estaba en la Spanish Art Gallery de Londres; en 1935 era propiedad de French and Co. de Nueva York y fue exhibido en el Brooklyn Museum, vendido a Charles Deering y revendido de nuevo por él a la citada sociedad. En 1953 fue comprado por el Museo de Cincinnatti. Max Friedlander infor ma sobre el retablo aunque no publica ninguna foto y desconoce su paradero.

6. FERRERAS, G. y MAGDALENO, R. (1997): "San Benito con los caballeros de Alfaro y Bravo de Lagunas y Virgen anunciada. Jan van Hemessen". PH. Boletín del Instituto Andaluz del Patrimonio Histórico, núm. 20 págs. 19-31.

7. El inventario dice exactamente así: "Ytem otro retablo de madera de flandes con la historia de Santa Catalina y la ymagen de Santa Catalina de bulto y un crucifijo de pincel con dos puertas en una San Sebastian y San Roque y en la otra San Benito con ciertas figuras/ en la capilla de Santa Catalina".

8. RODA PEÑA, J. (1996): Hermandades Sacramentales de Sevilla, págs. 190-194; PÉREZ DEL CAMPO, L (2000): Empresas arquitectónicas de la Hermandad Sacramental de san Vicente I y II. Boletín de las Cofradías de Sevilla núm. 496 y 497.

\section{PÉREZ DEL CAMPO, L. (2000-II) págs. 7I-74.}

10. Fundación Colombina. Archivo del Arzobispado. Sección Justicia. Leg. 3458: "Autos de pedimiento del Sr. Marqués el Prado sobre la posesión de la Capilla de Santa Catalina sita en la parroquia de San Vicente a que ha salido la Cofradía del Santisimo Sacramento de la dicha Iglesia"'.

| I. Ibidem, fol. 62

12. Escudo partido. En el primer cuartel (familia Alfaro) en campo de oro, dos bastones de sinoples y en campo de azur un creciente de plata ranvesado. En el segundo cuartel (Bravo de Lagunas), en campo de azur un castillo jaquelado de oro y gules puesto sobre ondas de azur y plata. La puerta del castillo de sable y en ella un león de oro rampante. Encima de la puerta un escudete de azur con flor de lis de oro y en jefe, sobre torrecillas laterales, dos águilas en su color natural y bordura de gules con ocho aspas de oro. En la grisalla de San Miguel Arcángel es escudo se timbra con casco. Como corresponde al símbolo de hidalguía, el casco se presenta adiestrado, de perfil, de acero bruñido, visera abierta dejando ver tres rejillas claveteadas de oro, perfilado de lo mismo. Orlado de lambrequines con fondos correspondientes al color del campo predominante y bordes al de la representación mayor.

Para mayor información puede verse: GABLBREATH, D. (1922): Manuel d'heraldique. Lausana; CASTAÑEDA Y ACOVER, V. (1954): Arte del Blasón. Manual de Heráldica. Madrid. CADENAS Y VICENT, V. (1975): Fundamentos de Heráldica. Madrid.

13. Sobre este linaje puede verse SÁNCHEZ SAUS, R. (1991): Linajes sevillanos medievales. Sevilla.

14. Archivo Histórico Provincial de Sevilla. Sección Protocolos Notariales. Escribano Juan Muñoz Naranjo, escritura de 19 de febrero de 1677. CUÉLLAR CONTRERAS, F. de P (1982). Documentos varios de Hermandades del siglo XVII. Boletín de las Cofradías de Sevilla, núm 272, mayo 1982 pág. 5.

15. Archivo Histórico Provincial de Sevilla. Sección Protocolos Notariales. Escribano García de León. Leg. 4925 s/f. Escritura de 14 de marzo de 1543.

16. Archivo Histórico Nacional. Órdenes Militares. Alcántara. Expedientes de ingreso. Expediente número 220. Real Cédula de 9 de julio de $153 \mid$ por la que se concede el hábito de la Orden de Calatrava a Sancho Bravo. http:// www.cervantesvirtual.com/historia/CarlosV/I53 I.shtml\#N-I 6 (Consulta de 23 de octubre de 200I).

17. Ídem. Real Cédula de I de diciembre de 1534

I8. PÉREZ DEL CAMPO, L: (2000-I) pág. 68.

19. FORONDA Y AGUILERA, M. (19|4): Estancias y viajes del emperador Carlos V. desde el día de su nacimiento hasta el de su muerte, comprobados y corroborados con documentos originales, relaciones auténticas, manuscritos de su época y otras obras existentes en los archivos y bibliotecas públicos y particulares de España y del extranjero, por... Madrid.

20. Archivo parroquia san Vicente. Libro Inventario de bienes |540-|55|, s/f.

2I. NIETO ALCAIDE, V. y CHECA CREMADES, F. (1989): El Renacimiento. Formación y crisis del modelo clásico. Madrid.

22. FERRERAS Y MAGDALENO (1997) pág. 21.

23. Archivo Histórico Nacional. Órdenes Militares. Alcántara. Expedientes de ingreso. Expediente número 249.

24. HERNANDEZ DÍAZ, J. (1977): "El templo hispalense de san Vicente". Boletín de la Real Academia de Bellas Artes, $2^{a}$ época núm. V, págs. I I5- 136.

Estas tablas están siendo objeto de restauración en la Facultad de Bellas Artes de la Universidad de Sevilla, por lo que no ha sido posible su estudio. 